\title{
Enhancement of Bio-Hydrogen Production in Chlamydomonas Reinhardtii by Immobilization and Co-Culturing
}

\author{
Saifuddin Nomanbhay ${ }^{*}, 1$, Priatharsini Purvunathan ${ }^{2}$ and Ong Mei Yin ${ }^{3}$ \\ Institute of Sustainable Energy, \\ Universiti Tenaga Nasional (The National Energy University) \\ Jalan IKRAM-UNITEN, 43000 Kajang, Selangor, Malaysia \\ ISaifuddin@uniten.edu.my, 2priatharsini.nathan@gmail.com, \\ 33me89475@hotmail.com
}

\begin{abstract}
Concerns about increasing greenhouse gas emissions are driving many countries to develop renewable energy sources. Enormous efforts are being directed towards the transition from fossil fuels to nonpolluting and renewable energy sources, one of which is bio-hydrogen. This paper explores the use of photosynthetic green microalgae Chlamydomonas reinhardtii immobilized in chitosan and co-cultured with ragi tapai to produce bio-hydrogen in a two-step process. Results show that the immobilization and presence of ragi tapai did not deter the microalgae from production of bio-hydrogen. It in fact enhanced the bio-hydrogen yield by microalgae plus it eases the process of cycling the microalgae cells between growth mode and hydrogen production mode. The maximum amount of bio-hydrogen produced by the microalgae when co-cultured with ragi tapai was $650000 \mathrm{ppm}$ and the best ratio was 1:0.25 (2 $\mathrm{g}$ microalgae:0.5 g ragi tapai).
\end{abstract}

Keywords: Microalgae, Chitosan, Ragi tapai, Bio-hydrogen, Immobilized microalgae cells

\section{Introduction}

Energy supply around the world is highly dependent on fossil fuels. The combustion of fossil fuels releases greenhouse gases (mainly $\mathrm{CO}_{2}$ ) and also results in formation of compounds such as $\mathrm{NO}_{\mathrm{X}}, \mathrm{SO}_{\mathrm{X}}, \mathrm{C}_{\mathrm{X}} \mathrm{H}_{\mathrm{y}}$, ash and sooth into the atmosphere; which will lead to global warming, environmental degradation and health problems. Thus to solve this issue, many research has been performed to replace the use of fossil fuel with energy source that are clean, renewable and environmentally friendly.

Hydrogen is one of the most plentiful molecules in the environment and is known as fuel of the future as it has higher density compared to carbon fuel and its usage produces only water as a by-product [1]. Hydrogen can be produced from fossil fuels as well as renewable sources. Currently hydrogen is being produced by conventional methods such as steam reforming of natural gas, which are energy intensive and are not very environmentally friendly [2]. The worldwide production of $\mathrm{H}_{2}$ currently has exceeded one billion $\mathrm{m}^{3} /$ day; mainly produced from natural gas $(48 \%)$, oil $(30 \%)$, coal $(18 \%)$, and the remaining $4 \%$ is produced from water splitting using electrolysis [3]. Hydrogen produced by living organism is called bio-hydrogen. Biological hydrogen production by biological process is of major interest currently as it can be operated at ambient temperature and pressure with minimal energy consumption and are more environmental friendly. Living organism such as microalgae and bacteria are able to produce hydrogen through the

${ }^{*}$ Corresponding Author 
process of photosynthesis. The hydrogen production by organisms can be broadly categorized into four primary groups which are direct bio-photolysis, indirect biophotolysis, photo fermentation and dark fermentation.

Bio-hydrogen production by microalgae through direct bio-photolysis is one of the well-studied methods. The biological pathway for hydrogen production, fundamentally, dependents upon the presence of hydrogen producing enzyme called hydrogenase. Hydrogenase catalyzes the chemical reaction of $2 \mathrm{H}^{+}+2 \mathrm{e}^{-} \leftrightarrow \mathrm{H}_{2}$. However, one of the main disadvantages of this process is the sensitivity of hydrogenase enzyme to oxygen. Oxygen is co-evolved together during bio-photolysis and when a certain amount of oxygen it present, the activity of hydrogenase is inhibited. Therefore, to overcome this problem, two-stage bio-photolysis through sulfur deprivation was developed. In this method, there is a temporal separation of the oxygenic photosynthesis and photobiological hydrogen production [4]. During the first stage, the microalgae cells are grown in sulfur rich medium to promote high growth rate and once sufficient growth has been reached, it will then be transferred into sulfur deprived medium for hydrogen production. Currently, the hydrogen yielded by biological processes is far too low compared to hydrogen produced by chemical systems [5]. Therefore, optimization of physiological assay and growth parameters are required in order to enhance the hydrogen production from biological process.

There are many studies that have been done to enhance the overall bio-hydrogen production yield by microalgae. This paper focuses on the enhancement of bio-hydrogen production through immobilization and co-culturing. Immobilization refers to the attachment or entrapment of cells into particular polymer matrices. The types of polymer matrices are polyacrylamide gel, agarose gel, alginate, chitosan, porous glass, and polyurethane among others. There have been many studies that exhibited improved production of hydrogen gas by immobilization of green algae cells. Laurinavichen et al. [6] used immobilized $C$. reinhardtii on Al-borosilicate porous glass sheets and saw an increased on the hydrogen production rate from 2.5 up to $4.3 \mathrm{~mL} \mathrm{~L}^{-1} \mathrm{~h}^{-1}$. Kosourov and Seibert [7] used alginate beads to immobilized $C$. reinhardtii and revealed higher cell density and hydrogen production rates $\left(12.51 \mathrm{~mol} \mathrm{mg}^{-1} \mathrm{Chl} \mathrm{h}^{-1}\right)$. They also reported that the alginate polymer helped to boost the hypoxic environment within the cells promoting hydrogen production conditions. Hence, the rate of hydrogen production can be greatly enhanced by using immobilized algae cells compared to free floating algae cells.

Co-culturing involves the pairing of green algae and photosynthetic bacteria which would enhance the overall hydrogen production rates. Photosynthetic bacteria are able to evolve hydrogen in the dark and light by utilizing fermentation products of green algae [8]. Moreover, co-culturing holds a promise of metabolic integration where microalgae generate organic carbon from $\mathrm{CO}_{2}$ and $\mathrm{H}_{2} \mathrm{O}$ while photosynthetic bacteria generate organic nitrogen via nitrogenase while both are producing hydrogen [9]. Wu et al. [10] co-cultured $B$. japonicum, a nitrogen-fixing bacterium species with $C$. reinhardtii strain 849 which is a cell wall deficient mutant and transgenic algal strain which was engineered to express the soybean $1 b a$ gene in its chloroplasts. Their finding showed that the hydrogen production in the co-culture increased 14.2 times higher for transgenic $1 b a$ strain and 5.5 times higher for $C$. reinhardtii strain 849 compared to the hydrogen production level of the green algae alone. Moreover, the oxygen content of both the cocultures decreased more quickly than the single algae culture [10]. The rapid decrease of oxygen content is due to the rapid respiration rate, promoting anaerobic conditions in the co-cultures which might lead to lower consumptions of aerobic respiration metabolism, higher Fe-hydrogenase activity leading to higher hydrogen production [10]. Thus, coculturing of photosynthetic bacteria with green algae is able to promote the enhancement of the overall hydrogen production yield.

In this present study, we investigate the yield of bio-hydrogen production by immobilizing the microalgae $C$. reinhardtii in chitosan and co-culturing it with ragi tapai. 
Ragi tapai is a traditional fermented food popular in Malaysia and Indonesia. The ragi tapai is cheaply available in local market. Microorganisms found in the traditional ragi tapai are moulds (Rhizopus oryzae, Amylomyces rouxii, Mucor sp. and Candida utilis) and yeasts (Saccharomyces cerevisiae, Saccharomycopsis fibuliger, Endomycopsis burtonii) [11]. The effect of co-culturing the microalgae with different ratio of ragi tapai was also investigated to determine the best ratio that gives the maximum amount of bio-hydrogen yield.

\section{Material and Methods}

\subsection{Materials}

2.1.1. Microalgae Culture Media: The microalgae species Chlamydomonas reinhardtii C137(+) was obtained from Culture Collection of Algae and Protozoa (CCAP) of SAMS Limited in United Kingdom, its strain number is CCAP 11/32A. C. reinhardtii was cultivated in Tris-acetate-phosphate (TAP) growth medium.

All the chemicals used in the growth medium were of analytical gradient. Ultrapure reversed osmosis (RO) water was obtained using the ELGA LabWater (UK) water purification system in our laboratory and was used to prepare all the solutions.

The TAP medium was prepared following the original TAP medium of Gorman and Levine [12]. For the preparation of sulfur free TAP medium, the sulfate salts were replaced with equimolar of chloride salts.

2.1.2. Culture Media and Ragi Tapai Cultivation: The ragi tapai was obtained from a local market and cultivated in YEP broth media. The YEP broth media preparation was adapted from Saifuddin and Refal [13]. The broth media consists of the following solutions: $10 \mathrm{~g} \mathrm{~L}^{-1}$ Yeast Extract, $10 \mathrm{~g} \mathrm{~L}^{-1}$ Peptone and $5 \mathrm{~g} \mathrm{~L}^{-1}$ Sodium Chloride $(\mathrm{NaCl})$ with $1 \mathrm{~L}$ Distilled Water $\left(\mathrm{H}_{2} \mathrm{O}\right) .200 \mathrm{~mL}$ of YEP broth media was autoclaved at $121^{\circ} \mathrm{C}$ for 15 minutes. It was then cooled down before adding in 6 grams of dry ragi tapai. The YEP broth media with ragi tapai were then aerobically propagated at $37^{\circ} \mathrm{C}$ while being shaken at $250 \mathrm{rpm}$ on a mechanical shaker. After about 24 hours, the ragi tapai were collected from the YEP broth media by centrifugation.

\subsection{Methods}

2.2.1. Cultivation of Microalgae: Fifteen milliliters $(\mathrm{mL})$ of $C$. reinhardtii were cultivated into $150 \mathrm{~mL}$ of TAP growth media as prepared previously. The microalgae cells were then left to be cultivated for 4 days at room temperature and were continuously illuminated from the top using cool white fluorescents light with an intensity of $200 \mu \mathrm{mol}$ $\mathrm{m}^{-2} \mathrm{~s}^{-1}(14800 \mathrm{Lux})$. The distance between the microalgae suspension and the fluorescent light was $25 \mathrm{~m}$ which was adequate in order to avoid photo inhibition. To avoid adherence of the microalgae to the sides of the culture flask, they were hand shaken once or twice daily. Cell density of the microalgae cell suspension were measured daily for 6 days using a spectrophotometer at $750 \mathrm{~nm}$.

2.2.2. Immobilization of Microalgae on Chitosan Beads: Immobilization of microalgae cells on chitosan beads was adapted from Kaya and Picard [14] with some slight modification. One gram of chitosan powder was dissolved in $50 \mathrm{~mL}$ of distilled water to get $2 \%(\mathrm{w} / \mathrm{v})$ of chitosan solution. It was then stirred and heated at $50^{\circ} \mathrm{C}$ on a hot plate. The $\mathrm{pH}$ of chitosan solution was adjusted to $\mathrm{pH} 5-5.5$ by dropwise addition of acetic acid. Once all the chitosan flakes have been dissolved, 2 grams of microalgae cells were added into the chitosan solution and left to be stirred for 30 minutes to get a homogenous suspension. Once a uniform suspension was achieved, the microalgae suspension was 
added dropwise into $200 \mathrm{~mL}$ of gently stirred $1.5 \%$ (w/v) sodium pyrophosphate $(\mathrm{pH} 7.5)$ using a model 100 push-pull syringe pump. It was then left to be stirred for 50 minutes for chelation. Then the cross linked-chitosan gel beads were washed 3 times with $0.1 \mathrm{M}$ phosphate buffer $(\mathrm{pH}$ 7.5) till the washing solution becomes neutral and were then stored in $\mathrm{RO}$ water.

2.2.3. Co-Culturing of Microalgae with Ragi Tapai: Microalgae and ragi tapai were immobilized on chitosan beads as mentioned in the section 2.2.2. Eight different ratios of ragi tapai were used to co-culture with the microalgae. Ratio of microalgae was held constant. The eight inoculation ratio was 1:1, 1:0.8, 1:0.5, 1:0.4, 1:0.25, 1:0.2, 1:0.125 and 1:01 (algae: ragi tapai).

2.2.4. Culture Conditions for Bio-hydrogen Production: Microalgae cells were harvested by centrifugation once it has reached a mid-exponential phase. It was then washed three times with TAP-S medium (TAP medium deprived of sulfur) before cultivated the microalgae cells in TAP-S medium. Two grams of free microalgae cells, 20 beads of immobilized microalgae and 20 beads of co-cultured microalgae with ragi tapai were suspended into $100 \mathrm{~mL}$ of TAP-S medium ( $\mathrm{pH} \mathrm{7).} \mathrm{The} \mathrm{bottles} \mathrm{were} \mathrm{sealed} \mathrm{tightly}$ with rubber cap in order to maintain an anaerobic condition and to prevent the outflow of hydrogen gas produced. The bottles were incubated using cool white florescent light illuminated continuously at $200 \mu \mathrm{mol} \mathrm{m} \mathrm{m}^{-2} \mathrm{~s}^{-1}(14800 \mathrm{Lux})$. It was left to be cultivated for 12 days and the gas that bubbles in the head space of the bottles were collected every day for 12 days using a gas tight syringe. Ten $\mathrm{mL}$ of the gas sample were drawn out from the headspace of the bottle using a gas tight syringe and inserted into the hydrogen meter (Tetra Gas Detector; Crowcon. UK) to measure the amount of hydrogen in the gas sample.

\subsection{Analytical Analysis}

2.3.1 Measurement of Microalgae Growth Rate: Growth of microalgae was deduced in terms of increase in optical density (OD) and biomass was quantified in terms of dry weight. OD of the microalgae was measured using Perkin Elmer Lamda 25 UV/VIS Spectrophotometer at a wavelength of 750 nanometers $(\mathrm{nm})$. Wavelength of $750 \mathrm{~nm}$ was chosen as it would not be interfered by chlorophyll absorbance. TAP medium was used as a blank to zero the spectrophotometer, four $\mathrm{mL}$ of microalgae were then withdrawn from the culture suspension and inserted into a cuvette to measure the OD.

For standard curve of the microalgae growth, 5 serial dilutions of microalgae were done. Four $\mathrm{mL}$ of the microalgae were pipette from the microalgae stock culture and its concentration were measured using spectrophotometer at $750 \mathrm{~nm}$. Then the microalgae were diluted by adding in $2 \mathrm{~mL}$ of TAP medium and its OD were measured. This process was repeated until the $\mathrm{OD}$ for $10 \mathrm{~mL}$ of diluted microalgae were obtained.

To measure dry weight, $10 \mathrm{~mL}$ of the diluted microalgae were filtered on pre-weighted filter paper. It was then dried at $70^{\circ} \mathrm{C}$ in the oven overnight. After 24 hours of drying, the weight of the paper was measured using an electronic analytical balance till a constant mass was obtained. As the dilution process used the same amount and concentration of microalgae, the biomass $(\mathrm{mg} / \mathrm{mL})$ for $2 \mathrm{~mL}$ of microalgae was twice the biomass for $4 \mathrm{~mL}$ of diluted microalgae. This concept was used to determine the biomass of different amounts of diluted microalgae.

2.3.2. Determination of Immobilized Microalgae Beads Cell Concentration: One bead of pure chitosan without cell coating was dissolved in $1 \mathrm{~mL}$ of $2 \%(\mathrm{v} / \mathrm{v})$ acetic acid solution and then smashed until it becomes a solution form at $\mathrm{pH} 5$. The solution of dissolved pure chitosan bead was used as blank to zero the spectrophotometer. Similarly, 
one bead of chitosan coated with microalgae cells was dissolved with acetic acid. Its optical density (OD) was measured at $750 \mathrm{~nm}$ in spectrophotometer. The OD of the microalgae beads were measured for 10 days continuously.

2.3.3. Measurement of Bio-hydrogen Production Yield: Bio-hydrogen production yield was determined by collecting the gas produced at the headspace of the bottle using a gas tight syringe. Ten $\mathrm{mL}$ of the gas sample was withdrawn and injected into the sensor of the hydrogen meter to obtain the amount of hydrogen gas.

2.3.4. Fourier Transformed Infrared (FTIR) Spectroscopy: FTIR was used to see the differences in the microalgae cells, immobilize microalgae cells and co-cultured microalgae cells. The instrument model used was Shimadzu IRPrestigae-21 (Shimadzu Cooperation Japan) equipped with temperature controlled DLATGS (deuterated L-alanin doped triglycine sulphate) detector. Spectra were processes using the IR solution window based software version 1.4 (Shimadzu). The scan settings were set as follows; resolution 8 $\mathrm{cm}^{-1}$, accumulation: 20 scans, measurement mode: transmittance $(\% \mathrm{~T})$, wave number: 4000 to $650 \mathrm{~cm}^{-1}$.

Before placing the sample, background measurement of air spectrum was performed. A drop of the sample was then placed on the surface of the horizontal ATR crystal disc at controlled temperature $\left(23^{\circ} \mathrm{C}\right)$. Spectra were then processed. After every scan, a new reference air background spectrum was taken. After performing the run, the sample was remove from the surface of the crystal disc and washed with acetone using a tissue.

\section{Results and Discussion}

\subsection{Cultivation of Microalgae}

Standard curve for microalgae growth was done to show the relationship between the biomass of microalgae cells and its optical density at $750 \mathrm{~nm}$. From the standard curve, the OD tie in directly with the biomass therefore the cell biomass can be determined without the need of measuring the cell's dry weight for each experiment. From Figure 1, the best fit line was obtained to determine an equation to be used for the later experiments. The correlation coefficient for equation (1) was 0.985 .

Dry Microalgae Biomass $(\mathrm{mg} / \mathrm{mL})=$ Biomass $=0.4565 \times \mathrm{OD}_{750 \mathrm{~nm}}+0.36$

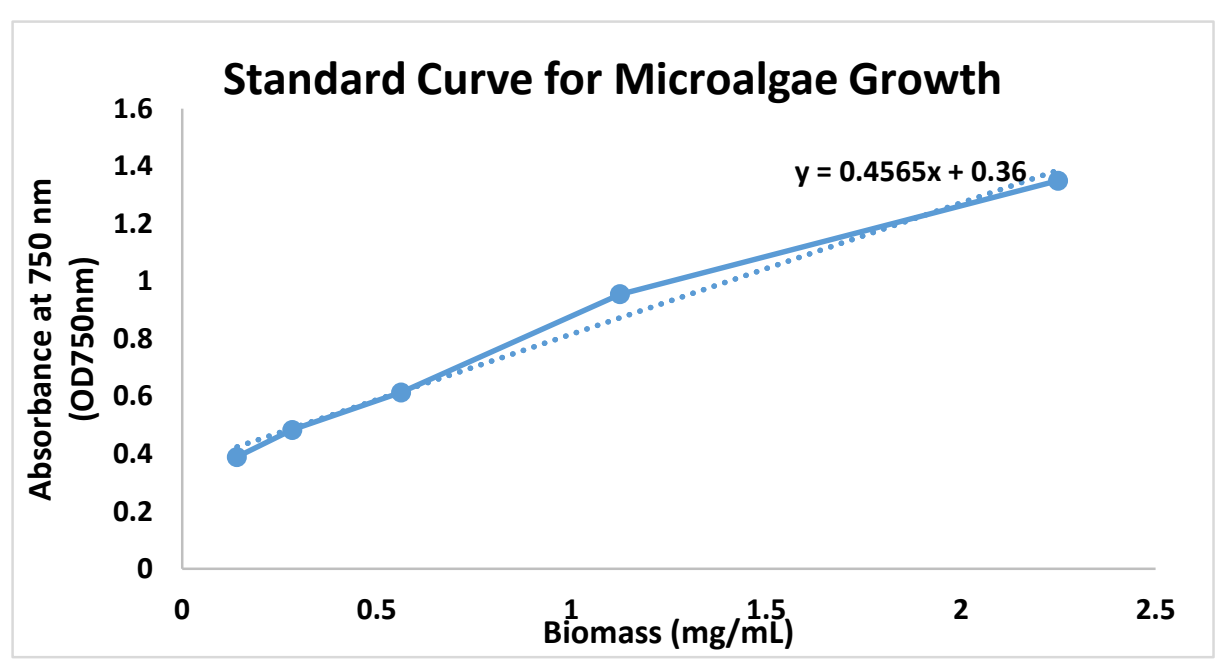

Figure 1. Standard Curve of C. reinhardtii Growth 


\subsection{Growth of Microalgae in TAP medium}

As can be observed in Figure 2, there is a clear pattern of the microalgae growth which can be characterized into five distinct phases. The first phase is the lag phase which is the period where the microalgae are starting to adapt to its new environment and grow slowly. The OD at lag phase increases slowly till it reaches the second phase which is the exponential phase. At the exponential phase, the microalgae will grow rapidly at its maximum growth rate and the microalgae population increases rapidly consuming all the nutrients available in the TAP medium. This would then lead to the third phase which is the diminishing growth phase, where the growth rate of the microalgae starts to decrease just slightly. As the nutrients becomes limited and metabolic by product increase, the microalgae cells then enter the fourth phase which is the stationary phase. At the stationary phase, the microalgae have already reached its maximal cell density capacity. Moreover, since all the nutrients have already been consumed, the growth of the microalgae eventually drops under the rate of deterioration leading to the last phase which is the death phase. At the death phase, the cell density starts to decrease and eventually stops growing due to lack of nutrients available in the TAP medium.

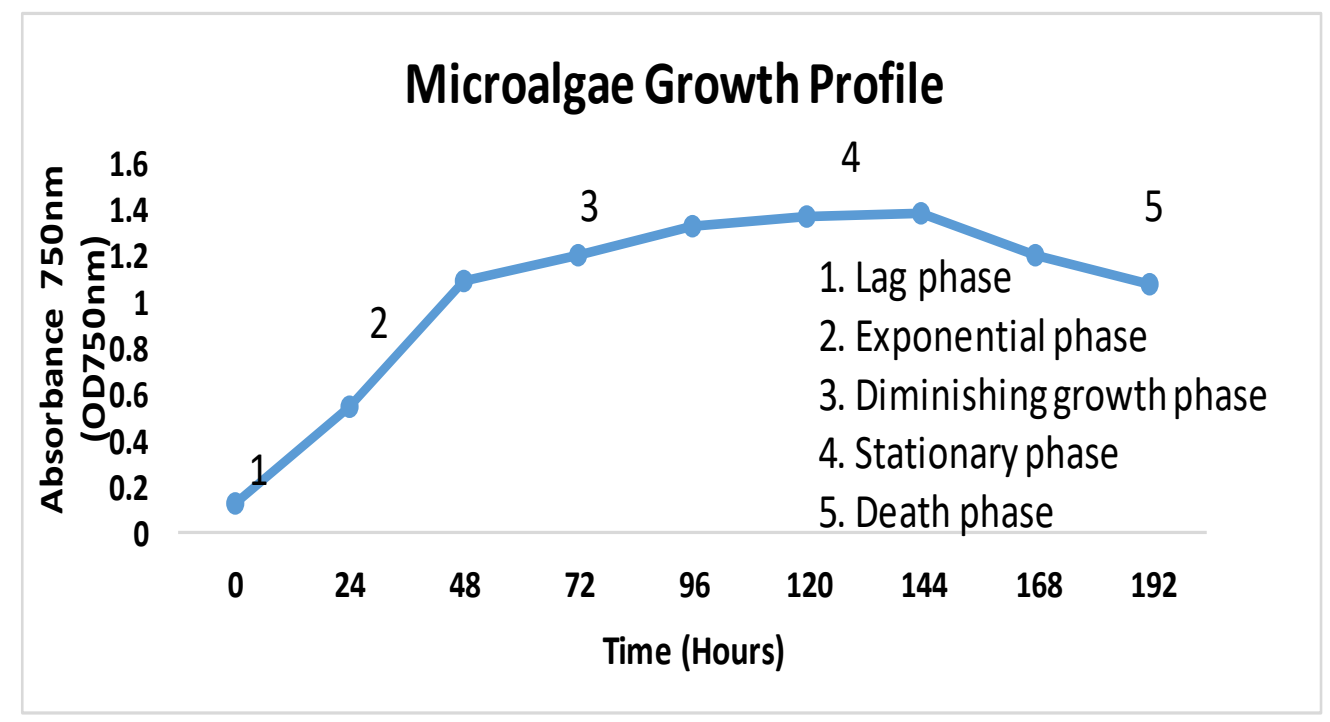

Figure 2. Growth of $C$. reinhardtii in TAP Medium

\subsection{Growth Assessment of immobilized Microalgae Cell Beads}

Chitosan immobilization with $C$. reinhardtii cells has not been studied comprehensively yet, hence it is important to analyze the growth and viability of the microalgae cells in the chitosan beads before it can be used for bio-hydrogen production. In order to determine if the microalgae cells are able to grow and retain when it is immobilized in chitosan beads, this experiment was done. As can be seen in Figure 3, growth was observed in the chitosan microalgae beads; however, it doesn't follow a typical growth curve. The growth curve of the immobilized microalgae cells has a longer period of lag phase due to the harsh $\mathrm{pH}$ changes during the immobilization procedure and also the amended chemical and physical conditions of the microalgae cells in the chitosan matrix. Hence, the microalgae cells in the chitosan beads were adapting to the changes before it starts to grow exponentially $[15,16]$. Permeability of the entrapment matrix, which simplifies the nutrient diffusion to the cells, the nutritional content of the medium, the chances of meeting light energy requirements and the thickness of the gel are the factors that affects the growth of the immobilized microalgae cells. 
The chelating agent used for crosslinking to immobilize the microalgae beads were sodium pyrophosphate $(\mathrm{pH}$ 7.5) and from the results obtained; it did not affect the diffusion of nutrients through the gel as the microalgae were still able to grow inside the chitosan beads. Moreover, this also shows that the use of chitosan for immobilization were not toxic to the microalgae cells as it does not inhibit the growth of the microalgae. The beads formed from this experiment were small in diameter, about $2 \mathrm{~mm}$ with maximum gel strength as it was able to withhold a substantial amount of microalgae cells. Kaya and Picard [17] surmise that the strong strength of the immobilized beads was due to the interaction of pyrophosphate with the single N-5 primary amine of chitosan. The free amine protonated groups are gelated by cross-linkage through chelate formation. Hence the longer the chitosan beads were treated in the pyrophosphate solution, a complete reaction of the pyrophosphate with the four protonated amines are able to form an acetal conformation [17]. The position where $\mathrm{P}_{2} \mathrm{O}_{7}{ }^{4-}$ is placed results in the strong and stable feature of the immobilized microalgae beads.

Good growth rates of the microalgae cells in chitosan beads shows that the immobilization technique used to immobilized the microalgae cells were ideal. Moreover, the retention efficiency of cell biomass and its high diffusivity of nutrients and gases which promotes growth confirm that chitosan is a good polymer matrix to immobilize microalgae cells.

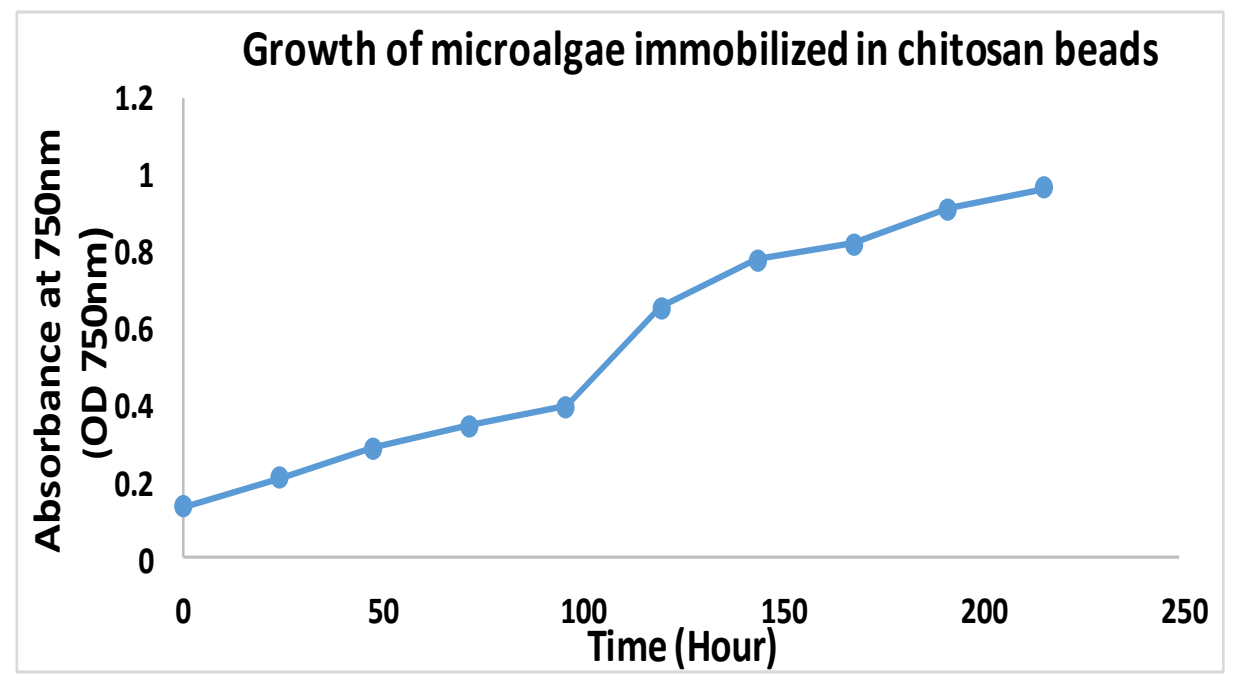

\section{Figure 3. Mean Values of Optical Density of C. reinhardtii Cultures Immobilized in Chitosan}

The growth of the microalgae in the chitosan beads can also be observed by the color of the microalgae beads. As can be seen in Figure 4, 5, and 6, initially the color of the microalgae beads was faint green and started to become greener. This is an indication that the microalgae cells are growing. The presence of green patches of colonies seen on the chitosan beads indicates the ability of the microalgae to grow in the chitosan beads. Moreover, the microalgae cells did not seep out from the chitosan beads when kept in the TAP medium for a long period of time. This shows the strength of the chitosan to be able to retain the microalgae cells in the beads. 


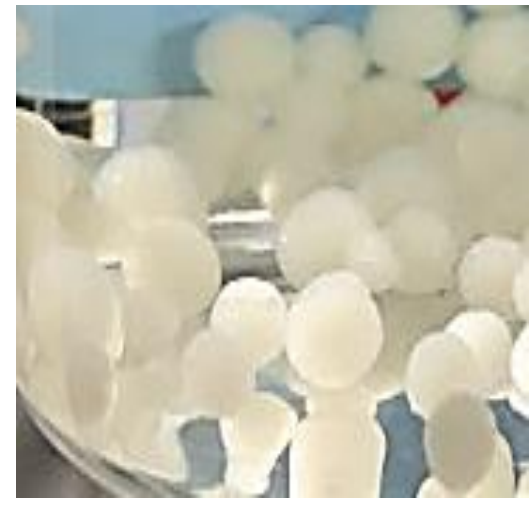

Figure 4. Chitosan Only Beads

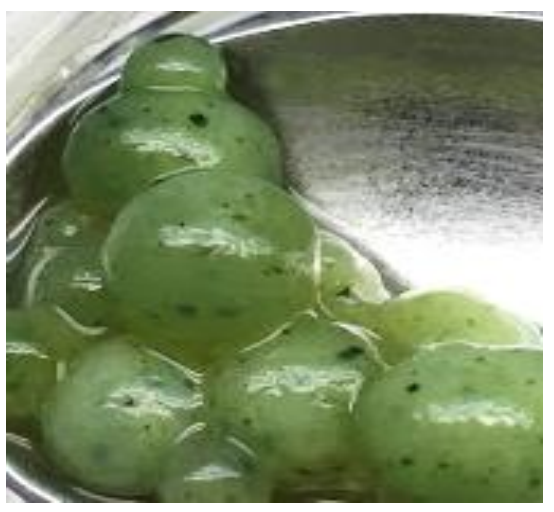

Figure 5. Immobilized Microalgae in Chitosan Beads Day 2

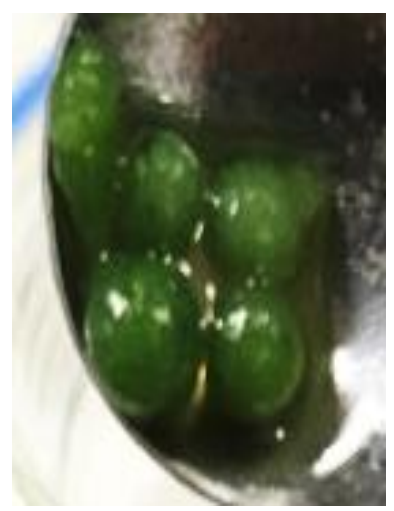

Figure 6. Immobilized Microalgae in Chitosan Beads Day 6

\subsection{Hydrogen Production using Free Microalgae cells}

Results obtained showed that $C$. reinhardtii were able to produce hydrogen under sulfur deprived conditions. As observed in Figure 7, hydrogen gas was produced after about 24 hours of incubating the free microalgae cells in sulfur deprived medium. This shows that sulfur plays a key role in regulating hydrogen production from $C$. reinhardtii. Initially the microalgae cultures were photoheterotrophically grown in sulfur rich growth media (TAP medium), and were then transferred to sulfur deprived growth media (TAP-S medium). Within 24 hours of sulfur deprivation, the oxygen evolution and carbon dioxide fixation declines significantly leading to anearobiosis. When sulfur was deprived from the growth medium, metabolism of the microalgae cells changes from aerobic photosynthetic growth to anaerobic resting state. Hydrogen production was maintained for 8 days before it ceased from being produced at 216 hours. The maximum amount of hydrogen gas was produced at 144 hours which was about $630000 \mathrm{ppm}$ of hydrogen gas. The lag time of 1 day before the production of hydrogen gas corresponds to the dissolved oxygen present in the culture. Hydrogen gas will only start being produced once the culture reaches a complete anaerobic stage with zero dissolved oxygen [18]. The free microalgae cell culture produced hydrogen gas for a period of about 168 hours.

The absence of sulfur during the first 24 hours of sulfur deprivation stops the synthesis of sulfurous amino acids. During this phase the microalgae culture starts storing as much of protein and starch as possible. Due to the inability of the cells chloroplast to synthesize substantial amount of cysteine and methionine, the D1 protein biosynthesis is impaired causing a defective PSII repair cycle [19]. The lack of D1 protein causes the incompetence of PSII repair cycle to repair PSII efficiently from photo-oxidative damage, eventually leading to loss of PSII activity. This then results in the accumulation of non- 
reducing QB (an intermediate in PSII repair cycle), preventing electron transfer from PSII to PSI $[19,20]$. Due to the fallout of the PSII activity, the rate of oxygen evolution drops below the rate of respiratory oxygen uptake as they are unable to sustain active photosynthesis and thus the microalgae culture shifts from an aerobic to anaerobic environment [4].

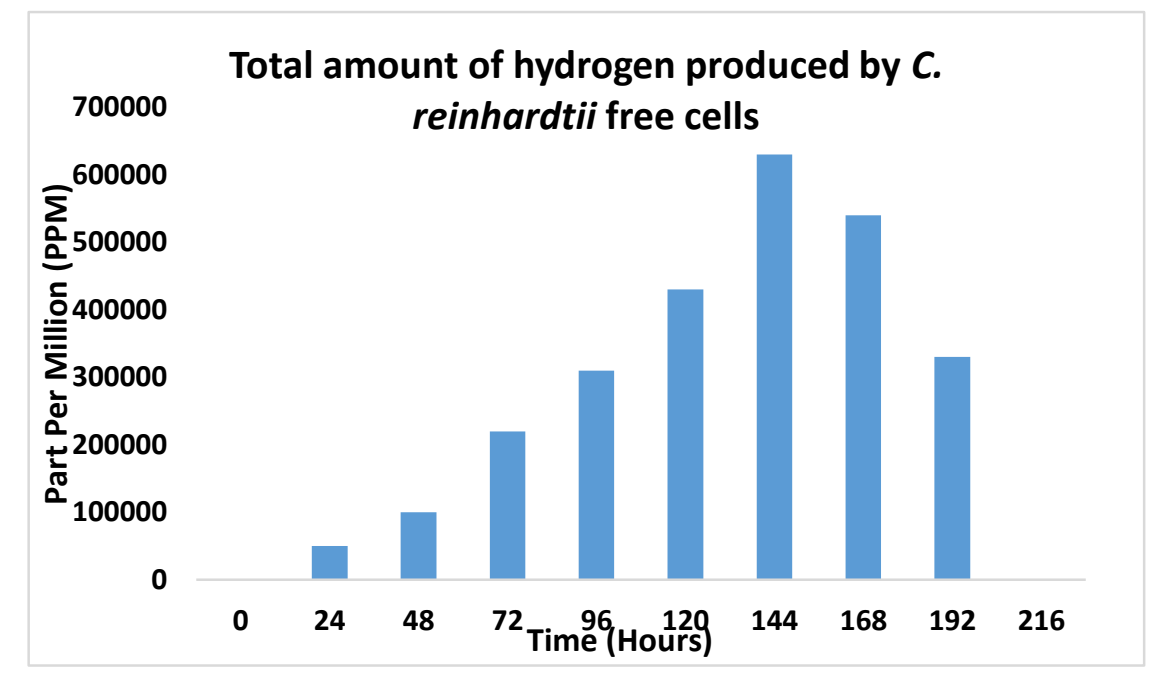

\section{Figure 7. Total Amount of Hydrogen Gas Produced by Free Microalgae Cells Cultured in Sulfur Deprived Medium (TAP-S)}

During the oxygen consumption phase, the levels of intracellular protein and starch were affected [20]. During the oxygen consumption phase, the starch and protein levels in the cell start to decrease $[4,21]$. The endogenous catabolism of starch and protein during sulfur deprivation was done to remove the oxygen generated photosynthetically by leftover PSII activity and maintains anaerobicity [22]. Increase in respiratory oxygen and gradual decrease in oxygen production results in net oxygen consumption eventually leading to an establishment of anaerobic environment (anaerobic phase). Sulfolipid sulfoquinovosyl diacylglycerol (SQDG), a type of sulfolipid located in the chloroplast membrane of the microalgae, is degraded during the oxygen consumption phase of as a source of sulfur to maintain the synthesis of essential enzymes and proteins before the degradation of RuBisCO starts [23, 24]. A few days after sulfur deprivation, the enzyme $\mathrm{RuBisCO}$ was also degraded, resulting in the inactivation of Calvin cycle hence carbon dioxide fixation is ceased [25]. This results in net production of carbon dioxide, considering the low but significant carbon dioxide production rate [4]. RuBisCO pool contains high amount sulfurous amino acids, which was useful for the microalgae cells [26]. It serves as an intracellular sulfur source since Calvin cycle is halted.

Drop of photosynthetic activity below that of respiration induces the sulfur deprived $C$. reinhardtii to rapidly consumes all dissolved oxygen and becomes anaerobic under continuous illumination. This consequently leads to the activation of the reversible hydrogenase enzyme and production of hydrogen gas (hydrogen production phase). Since PSII function remains inactivated, plastoquinone, cytochrome b6-f and PS I are responsible for transporting electrons from organic and endogenous substrate to ferredoxin and hydrogenase [22, 27]. Production of hydrogen gas is a way for the microalgae to generate adequate amount of ATP for the survival of the microalgae cells. This is because the main processes for ATP production are through mitochondrial respiration and oxygenic photosynthesis; but those two process are not available in sealed and sulfur deprived microalgae cells considering oxygen is not present and PS II function is inactivated [4]. Therefore, electron transport from endogenous organic substrate 
through the PQ pool, Cyt b6-f complex preserves the electron transport process generates $\mathrm{pH}$ gradient across the thylakoid membrane for the production of sufficient amount of ATP $[4,27]$. On the other hand, the light dependent electron transport by PS I activity though ferredoxin and hydrogenase produces molecular hydrogen to maintain the electron transport process and consequently the $\mathrm{pH}$ gradient enabling the cell to endure the nutrient deprivation conditions $[4,27]$. Moreover, since the Calvin cycle has ceased, the system will be in a reduced state as the Calvin cycle can no longer function as a sink for carbon and energy, therefore the cell depends on the release of electrons from the system to avoid oxidative damage [28]. Thus, hydrogenase enzyme catalyzes the production of hydrogen by electrons received from ferredoxin to release the reductive pressure in the anaerobic environment [29]. In short, the regulation of the photosynthetic electron transport is an essential aspect of adjusting the cells metabolism to nutrient availability. The microalgae C. reinhardtii adapts to anaerobic photosynthetic metabolism during the loss of oxygen in order to generate ATP for the survival of the cells [18].

As the hydrogen gas is being produced, various metabolites are excreted as byproducts. Some of the metabolites excreted are such as formate, ethanol, succinate and amino acids [20, 30, 31]. Eventually after a longterm effect of sulfur deprivation, hydrogen production deliberately deteriorates till it stops. The microalgae cells then enter the last phase which is the termination phase. Accumulation of the metabolites could also be one of the reasons for the termination of hydrogen production [31].

\subsection{Hydrogen Production using Immobilized Microalgae Cells}

The immobilized microalgae cells started producing hydrogen gas after 72 hours of sulfur deprivation. It went through a 3 days of lag phase before being able to produce hydrogen gas. The longer lag phase was due to the harsh conditions that the microalgae cells went through during the immobilization process hence, part of the microalgae cells might be inactivated. Furthermore, high packing density restrains the exposure of light to the microalgae cells making them less active hence it has to be exposed to light for a longer period of time before being able to produce hydrogen gas [32]. As shown in figure 8 a significant increase in the amount of hydrogen gas produced occurred after 72 hours of sulfur deprivation and reached a maximum at 192 hours, producing $450000 \mathrm{ppm}$ of hydrogen gas. It continued to produce hydrogen gas for 8 days before it came to a halt at 264 hours. The immobilized microalgae cells produced hydrogen for a period of about 168 hours.

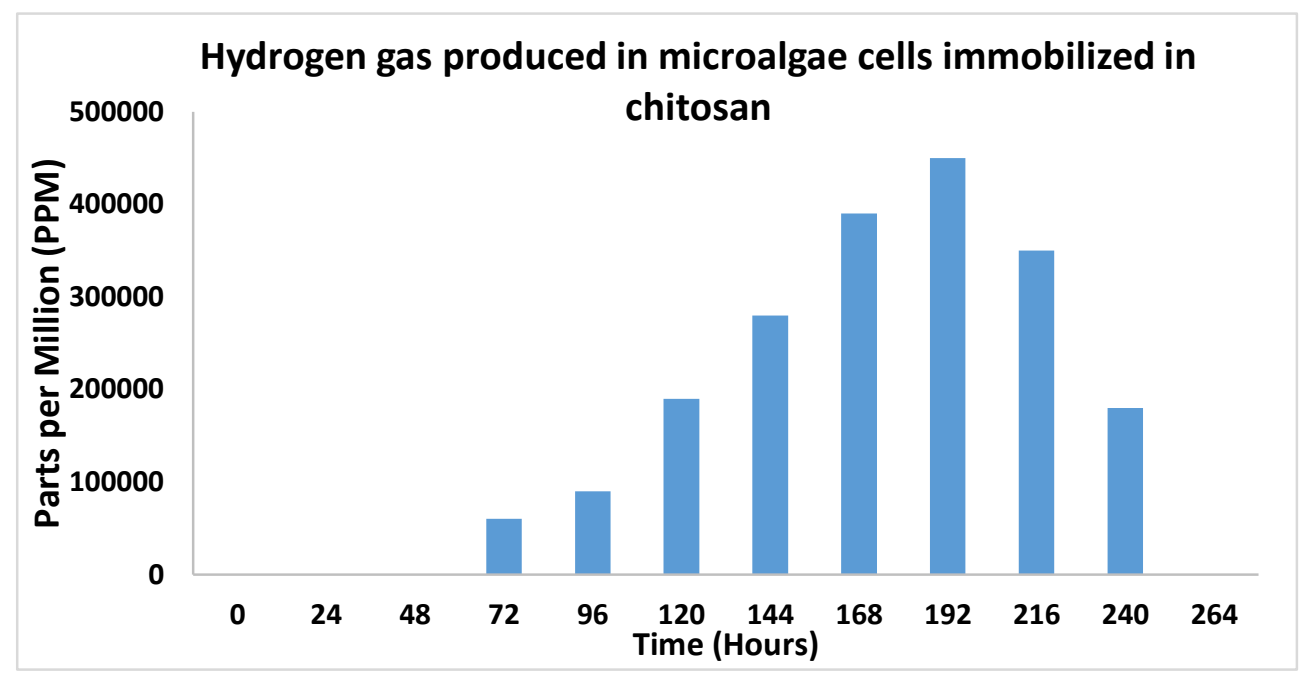

Figure 8. Total Amount of Hydrogen Gas Produced in Microalgae Cells Immobilized in Chitosan Beads 
Immobilization of $C$. reinhardtii cells using chitosan for hydrogen production has not been attempted before by other researchers previously. Although they have been immobilized with other immobilizing agents, the amount of hydrogen produced is lower compared to when immobilized using chitosan. Previously, when $C$. reinhardtii was immobilized using al-borosilicate the highest amount of hydrogen produced was $45 \mathrm{ml}$ which is about $45000 \mathrm{ppm}$ [6]. Whereas when $C$. reinhardtii was immobilized with alginate, the total amount of hydrogen gas evolved was $67 \%$ which was about 670000 ppm [33]. Hence, it can be concluded that, hydrogen productions by chitosan immobilized C. reinhardtii are much higher compared to al-borosilicate and alginate immobilized $C$. reinhardtii. Moreover, chitosan is a natural polymer (biodegradable and environmental friendly) that has higher nutrient and product diffusion rate and is also more environmental friendly. This makes chitosan the best polymer to immobilize microalgae cells.

Results from this experiments shows that it is possible to achieve sustainable hydrogen production by immobilizing $C$. reinhardtii cells in chitosan and subjecting them to sulfur deprived conditions. Although the total hydrogen gas produced by chitosan immobilized cells is slightly below that of free algae suspension, it is still in a comparable level. Since microalgae cells are required to be suspended in liquid medium, it is difficult to cycle the microalgae cells between sulfur containing medium and sulfur depleted medium as it requires centrifugation step which are energy and time consuming. Moreover, the required repetitive washing of microalgae cells with sulfur free medium is time consuming, energetically inefficient, susceptible to contamination and has high possibility of losing the microalgae cells [34]. Therefore, the availability of immobilized microalgae cell to produce hydrogen under sulfur deprived conditions makes it practically easier to cycle the cells between the two medium, plus it is quicker, simpler and cheaper than using suspension cell cultures [6]. In addition, the chitosan polymer helps to maintain and enhance the hypoxic environment in the vicinity of the cells, boosting conditions for hydrogen production [9]. It was also reported that the light conversion efficiency in suspension cultures are low $(0.24 \%)$ [35]. Immobilization of microalgae cells with chitosan forming small beads allows for greater and more efficient utilization of light per area basis [36].

\subsection{Hydrogen Production by Microalgae Co-cultured with Ragi Tapai}

For the co-culturing strategies, instead of using photosynthetic or fermentative bacteria, ragi tapai was used. Ragi tapai contains a consortium of microorganism in it which mainly consists of moulds, yeast and bacteria. Results obtained from this experiment showed that co-culturing the microalgae $C$. reinhardtii with ragi tapai helps to improve the biohydrogen production as can be seen on figure 9. The amount of microalgae was held constant, whereas the amount of ragi tapai was altered. Various ratios of microalgae to ragi tapai were tested and the result indicated that it had an influence on the amount of hydrogen produced. All ratios of microalgae to ragi tapai had a lag phase of 4 days before it started to produce hydrogen at 96 hours (day 5). The lag phase was expected as during the immobilizing process of the microalgae and ragi tapai, both were expose to chemical and physical alteration of in the chitosan matrix. Hence the co-cultured cells had to adapt to the changes before it is able to produce hydrogen.

As depicted in Figure 9, the optimal inoculation ratio of microalgae to ragi tapai was 1:0.25 (2 g microalgae and $0.5 \mathrm{~g}$ ragi tapai). Hydrogen production for 1:0.25 ratio lagged in the first 4 days but increased significantly from day 5 (96 hours) onwards and reached the highest amount of hydrogen produced at day 8 (168 hours). The highest amount of hydrogen produced was $650000 \mathrm{ppm}$. After 168 hours the amount of hydrogen produced by the co-cultures started to decrease slightly before it ceased to produce at 216 hours. The control system (microalgae only), had highest production of hydrogen at day 6 (120 hours). Although it produced the maximum amount of hydrogen earlier than ratio of 
1:0.25 of the co-culture system, the amount of hydrogen produced was lesser, which was only $590000 \mathrm{ppm}$. Moreover, for the microalgae only culture, the hydrogen production started to decrease rapidly after 120 hours.

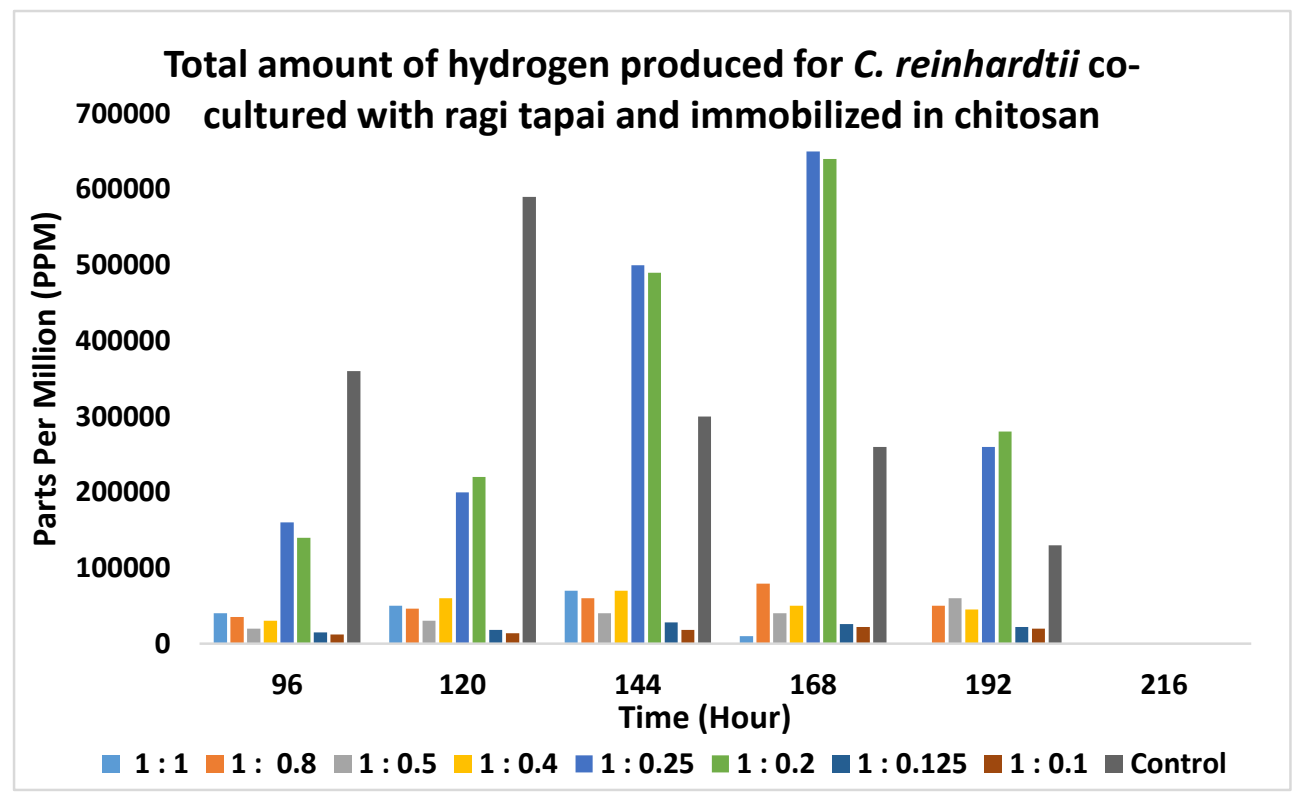

\section{Figure 9. Hydrogen Accumulation in The Headspace of Co-Cultured $C$. Reinhardtii and Ragi Tapai}

It is clearly showed that the amount of hydrogen produced by $C$. reinhardtii is effected by the inoculation ratio of ragi tapai to microalgae. Amount lower than this $(0.5 \mathrm{~g}$ per $2 \mathrm{~g}$ of microalgae) would be too little and do not show any significant improvement. A possible reason for the decrease in amount of hydrogen produced when the ratio of ragi tapai is increased above the $0.5 \mathrm{~g}$ ragi tapai per $2 \mathrm{~g}$ microalgae, could be because of production of fermentation metabolites by the ragi tapai during the cultivation period; that could interfere with the hydrogen metabolism of $C$. reinhardtii [37]. The metabolites produced by the ragi tapai could be harmful to the microalgae thus when high amount of ragi tapai was cultured, it produces more of the metabolites which effected the hydrogen process of the algae leading to decrease in hydrogen production. Moderate ratio of algae to ragi tapi improved the hydrogen production.

To the best of the author's knowledge this is a first study where ragi tapai have been used as the co-culturing agent with microalgae. A reason ragi tapai was chosen to be cocultured with $C$. reinhardtii because it has a consortium of microorganism in it, and hence the mixture of the microorganism could help one another to enhance the production of hydrogen by microalgae. Moreover, it is readily and cheaply available in many countries like Malaysia and Indonesia because it is used as a food ingredient. One of the main possible reason for the enhanced in hydrogen production by the co-cultures of microalgae and ragi tapai was because of the increase in the respiration rate of the co-cultures. The microorganisms in ragi tapai will consume the oxygen evolved by the microalgae and hence, helps to maintain an anaerobic environment for the microalgae to evolve hydrogen without causing any detrimental effect on the photosynthetic apparatus of the algae [38]. The accelerated consumption of oxygen by ragi tapai helps to improve the anaerobic induced activity of microalgae's hydrogenase, leading to enhance improvement in hydrogen produced. Hence the high respiratory rates and oxygen consumption in the microalgae-ragi tapai co-cultured system is a directly responsible for the enhanced hydrogen production. Another possible reason could be that, $C$. reinhardtii produces 
organic acids such as formate and acetate during the fermentation process of hydrogen production [39]. It could be likely that the excreted metabolites from $C$. reinhardtii are used by ragi tapai as feedstock to produce hydrogen by its own, leading to enhance in the overall hydrogen production by the co-cultured system. Therefore, the ability of the ragi tapai to utilize the fermentation products of the microalgae may help to improve the overall hydrogen production.

Another explanation that has been reported in literature regarding the enhancement of hydrogen production by microalgae using co-culturing system is that the improvement of range of light spectrum for photosynthesis. Photosynthetic hydrogen production by green microalgae uses the visible region of light spectrum $(400-700 \mathrm{~nm})$, whereas ragi tapai which contains a mixture of microorganism uses the near infrared region $(700-950 \mathrm{~nm})$ of the solar spectrum [40]. Hence combination of both microalgae and ragi tapai broadens the range of solar spectrum allowing improved utilization of the light for photobiological hydrogen production [9].

With the finding from this study and supported by other works as mentioned above, the co-cultured system is much more beneficial than an microalgae only system. Microalgae only system produces low hydrogen yield due to limited efficiency for hydrogen production [41]. Co-cultured system produces higher hydrogen yield compared to microalgae only system due to the symbiotic effect between the microalgae and ragi tapai, where they work in harmony to provide stability in the hydrogen production process [42]. Co-cultured system provides better performance and is able to overcome the limitations faced by microalgae only culture. Moreover, using a co-culture system eliminates the use of reducing agents and eliminates the step of inert gas sparging into the culture medium during the hydrogen production process to remove as much as oxygen as possible. Therefore, it reduces the overall cost of hydrogen production as it avoids the usage of expensive reducing agents and gases.

This study demonstrated the ability of using a cheaply and readily available ragi tapai to be co-cultured with $C$. reinhardtii to enhance its hydrogen production. Furthermore, ragi tapai has no toxic effect to the algae, in fact it helps to increase the respiration rates in the co-culture leading to a rapid oxygen consumption, improvement in the hydrogenase activity and maintaining an anaerobic environment, consequently leading to an enhanced hydrogen production. The co-culture system together with immobilization results in significant improvement in hydrogen production.

\subsection{Fourier Transformed Infrared Spectroscopy Analysis (FTIR) Analysis}

The sequential transformation of microalgae cells via immobilization and co-culturing was assessed by FTIR spectroscopy. The FTIR spectroscopy can be used as a rapid detection and identification method for any changes occurring during a chemical reaction within the biochemical structure and composition of the cellular constituents. 


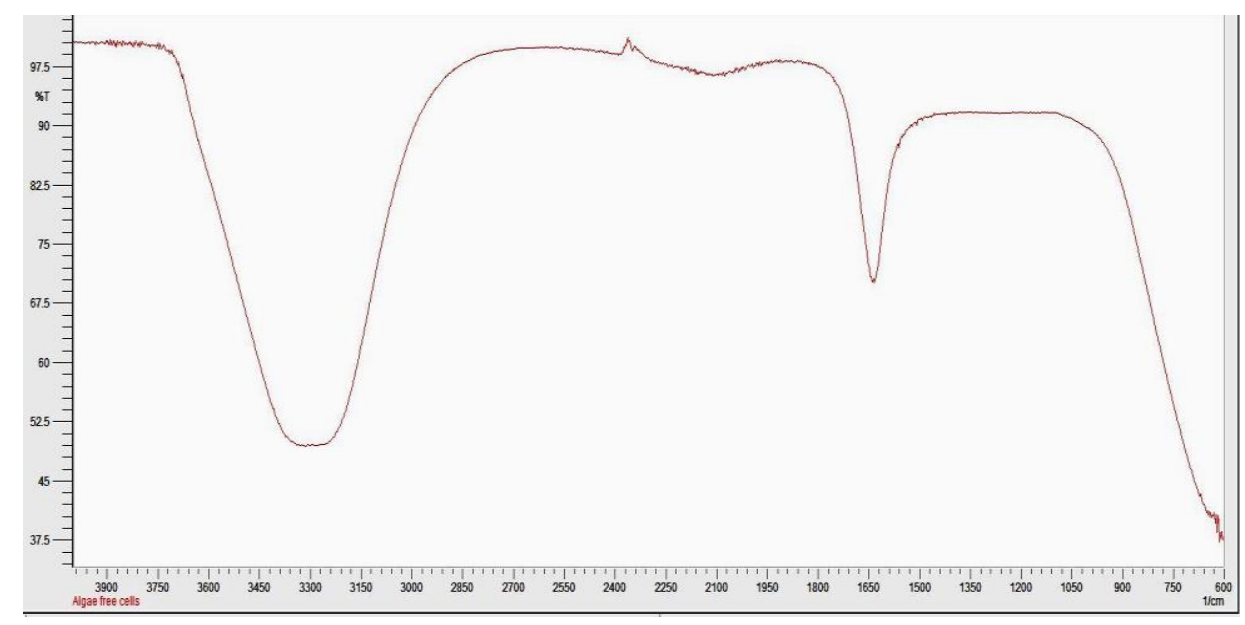

Figure 10. FTIR Chromatogram on Free Microalgae Cells

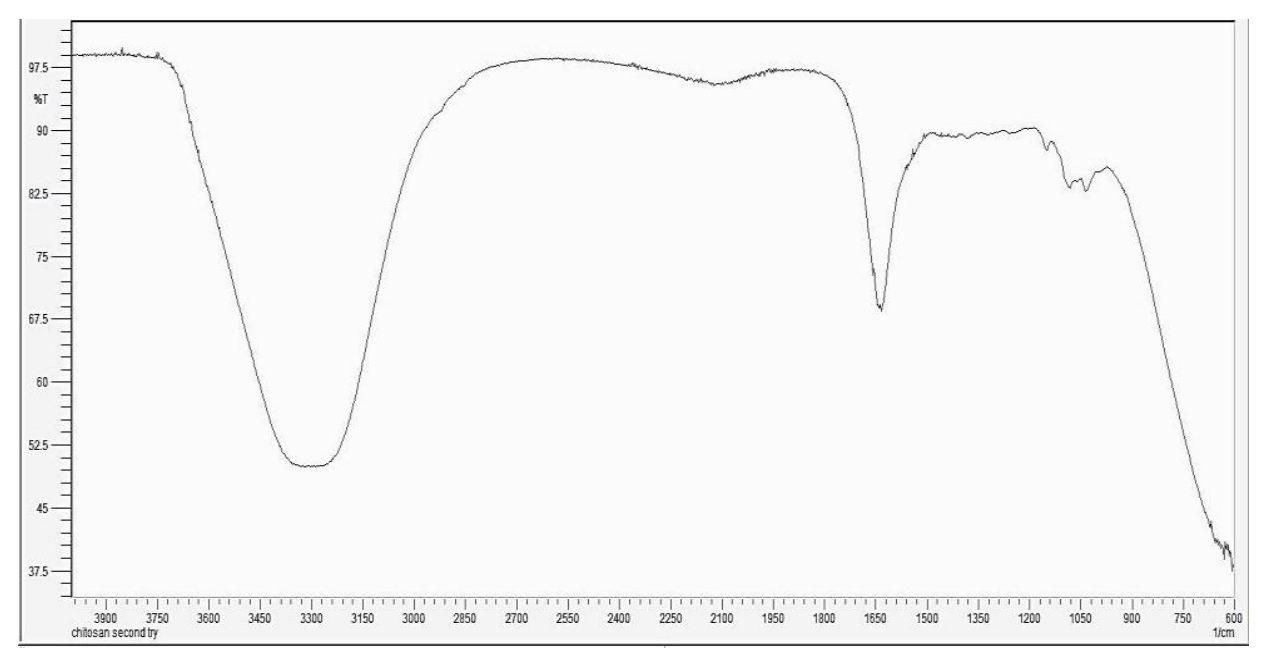

Figure 11. FTIR Chromatogram on Chitosan Only Beads

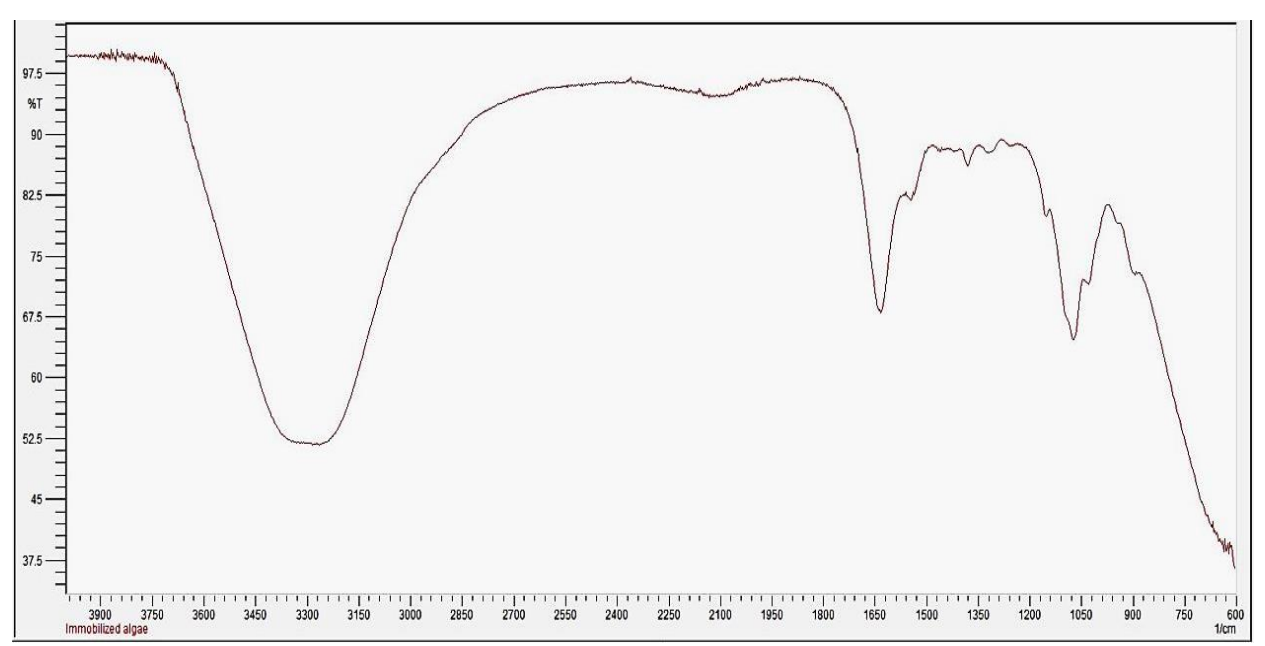

Figure 12. FTIR Chromatogram on Immobilized Microalgae Cells in Chitosan Bead 


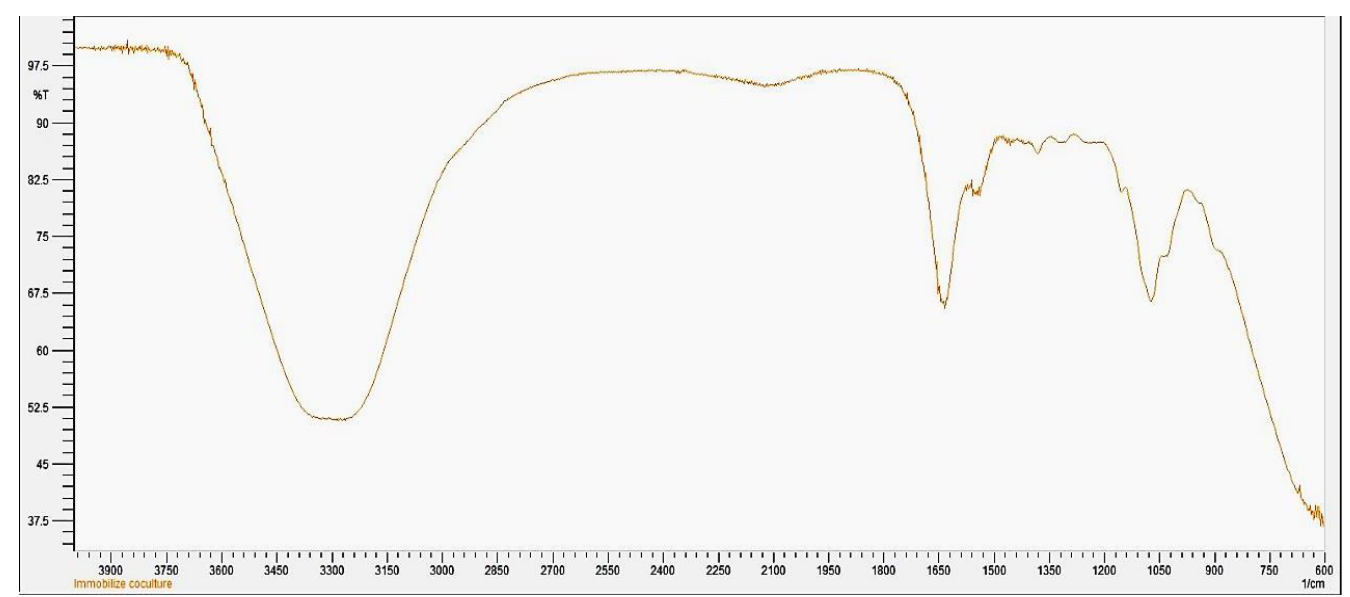

Figure 13. FTIR Chromatogram on Microalgae Cells Co-Cultured with Ragi Tapai and Immobilized in Chitosan Bead

Figure 11 has three small peaks with bandwidth centered at wavenumber 1000 to 1200 $\mathrm{cm}^{-1}$ due to the presence of C-N stretching of amines group. Figure 12 and Figure 13 has C-N stretching of amines group but only one slightly long peak with bandwidth centered between 1050 and $1100 \mathrm{~cm}^{-1}$. Moreover, they both have a $\mathrm{S}=\mathrm{O}$ stretching of sulfate group peak with bandwidth centered at wavenumber between 1350 and $1400 \mathrm{~cm}^{-1}$. This shows that the new peaks seen for immobilized microalgae and immobilized co-cultured microalgae are due to the interaction between the chitosan and the microalgae (amine group and the sulfate group). Hence the reaction performed during the immobilization and co-culturing with ragi tapai was successful.

\section{Conclusion}

Based on the outcomes of this research, it is concluded that the green algae, Chlamydomonas reinhardtii can be successfully be immobilized in chitosan beads and are able to produce bio-hydrogen. Even though the maximum amount of bio-hydrogen produced were slightly lower than the free microalgae cells, the value is still comparable and in fact it is much simpler and cost effective to use immobilized microalgae cells for bio-hydrogen production than free microalgae cells.

Furthermore, immobilized co-cultures of $C$. reinhardtii and ragi tapai were able to produce maximum amount of bio-hydrogen which is even higher than free microalgae cells and immobilized microalgae cells. Co-culturing of microalgae cells with ragi tapai didn't hinder the microalgae cells to produce bio-hydrogen but it helps the microalgae cells to increase its bio-hydrogen yield. The best ratio to produce the highest amount of bio-hydrogen from the co-culture was 2 grams of algae with 0.5 grams of ragi tapai.

To conclude, the results showed that it was accomplishable to enhance the overall yield of bio-hydrogen by immobilizing the microalgae cells and co-culturing it with ragi tapai. This current work provided expanded insight into the process of enhancing bio-hydrogen production for a better understanding to establish an optimized environment. Some future work that can be carried out is further optimized the conditions to enhance bio-hydrogen production yield.

\section{Acknowledgments}

The authors would like to thank Malaysian Ministry of Higher Education (MOHE) for valuable financial support through the Fundamental Research Grant Scheme (FRGS) (FRGS/2/2014/SG01/UNITEN/02/1). We also acknowledge the Universiti Tenaga Nasional for the research facilities. 


\section{References}

[1] H. Argun and F. Kargi, "Bio-hydrogen production by different operational modes of dark and photofermentation: an overview", International Journal of Hydrogen Energy, vol. 36, no. 13, (2011), pp. 7443-7459.

[2] R. N. S. Shaishav and T. Satyendra, "Biohydrogen from algae: Fuel of the Future", International Research Journal of Environment Sciences, vol. 2, no. 4, (2013), pp. 44-47.

[3] S. V. Mohan and A. Pandey, "Biohydrogen production: An introduction. In Biohydrogen", Elsevier, Amsterdam, (2013), pp. 1-24.

[4] A. Melis, L. P. Zhang, M. Forestier, M. L. Ghirardi and M. Seibert, "Sustained photobiological hydrogen gas production upon reversible inactivation of oxygen evolution in the green alga Chlamydomonas reinhardtii”, Plant Physiology, vol. 122, no. 1, (2000), pp. 127-136.

[5] K. Srirangan, M. Pyne and C. P. Chou, "Biochemical and genetic engineering strategies to enhance hydrogen production in photosynthetic algae and cyanobacteria", Bioresource Technology, vol. 102, no. 18, (2011), pp. 8589-8604.

[6] T. V. Laurinavichene, A. S. Fedorov, M. L. Ghirardi, M. Seibert and A. A. Tsygankov, "Demonstration of sustained hydrogen photoproduction by immobilized, sulfur-deprived Chlamydomonas reinhardtii cells", Int. Journal Hydrogen Energy, vol. 31, no. 5, (2006), pp. 659-667.

[7] S. N. Kosourov and M. Seibert, "Hydrogen photoproduction by nutrient-deprived Chlamydomonas reinhardtii cells immobilized within thin alginate films under aerobic and anaerobic conditions", Biotechnol. Bioeng, vol. 102, no. 1, (2009), pp. 50-58.

[8] K. Miyamoto, S. Ohta, Y. Nawa, Y. Mori and Y. Miura, "Hydrogen production by a mixed culture of a green alga, Chlamydomonas reinhardtii and a photosynthetic bacterium, Rhodospirillum rubrum", Agricultural and Biological Chemistry, vol. 51, no. 5, (1987), pp. 1319-1324.

[9] E. Eroglu and A. Melis, "Photobiological hydrogen production: Recent advances and state of the art", Bioresource Technology, vol. 102, no. 18, (2011), pp. 8403-8413.

[10] S. Wu, X. Li, J. Yu and Q. Wang, "Increased hydrogen production in co-culture of Chlamydomonas reinhardtii and Bradyrhizobium japonicum, Bioresource Technol, vol. 123, (2012), pp. 184-188.

[11] I. Gandjar, "Tapai from cassava and cereals", Proceedings of the $1^{\text {st }}$ International Symposium and Workshop on Insight into the World of Indigenous Fermented Foods for Technology Development and Food Safety, Kasetsart University, (2003), pp. 1-10.

[12] D. S. Gorman and R. P. Levine, Proc. Natl. Acad. Sci. USA 54, (1965), pp. 1665-1669.

[13] N. Saifuddin, and H. Refal, "Microwave Assisted Bioethanol Production from Sago Starch by CoCulturing of Ragi Tapai and Saccharomyces Cerevisiae", Journal of Mathematics and Statistics, vol. 7, no. 3, (2011), pp. 198-206.

[14] V. Kaya and G. Picard, "Stability of chitosan gel as entrapment matrix of viable Scenedesmus bicellularis cells immobilized on screens for tertiary treatment of wastewater", Bioresource Technology, vol. 56, no. 2-3, (1996), pp. 147-155.

[15] B. A. May and M. del Pilar Sánchez-Saavedra, "Growth and removal of nitrogen and phosphorus by free-living and chitosan-immobilized cells of the marine cyanobacterium Synechococcus elongates", Journal Appl Phycol, vol. 21, no. 3, (2008), pp. 353-360.

[16] N. Mallick, "Biotechnological potential of immobilized algae for wastewater N, P and metal removal: A review”, Biometals, vol. 15, no. 4, (2002), pp.377-390.

[17] V. M. Kaya and G. Picard, G., "The viability of Scenedesmus bicellularis cells immobilized on alginate screens following nutrient stravation in air at 100\% relative humidity", Biotechnol. Bioeng, vol. 46, (1995), pp. 459-464.

[18] S. Oncel and F. V. Sukan, "Effect of light intensity and the light: dark cycles on the long term hydrogen production of Chlamydomonas reinhardtii by batch cultures", Biomass and Bioenergy, vol. 35, no. 3, (2011), pp. 1066-1074.

[19] D. Wykoff, J. Davies, A. Melis and A. Grossman, "The regulation of photosynthetic electron transport during nutrient deprivation in Chlamydomonas reinhardtii”, Plant Physiology, vol. 117, no. 1, (1998), pp. 129-139.

[20] S. Kosourov, M. Seibert and M. Ghirardi, "Effects of Extracellular pH on the Metabolic Pathways in Sulfur-Deprived, H2-Producing Chlamydomonas reinhardtii Cultures: Plant and Cell Physiology, vol. 44, no. 2, (2003), pp. 146-15 5.

[21] S. Kosourov, A. Tsygankov, M. Seibert and M. L. Ghirardi, "Sustained hydrogen photoproduction by Chlamydomonas reinhardtii: Effects of culture parameters:, Biotechnol. Bioeng, vol. 78, (2002), pp. 731-740.

[22] M. L. Ghirardi, J. P. Zhang, J. W. Lee, T. Flynn, G. E. Seibert and A. Melis, "Microalgae: a green source of renewable H2", Trends in Biotechnology, vol. 18, no. 12, (2000), pp. 506-511.

[23] K. Sugimoto, N. Sato and M. Tsuzuki, "Utilization of a chloroplast membrane sulfolipid as a major internal sulfur source for protein synthesis in the early phase of sulfur starvation in Chlamydomonas reinhardtii”, FEBS Lett., vol. 581, (2007), pp. 4519-4522. 
[24] N. Sato, K. Sonoike, M. Tsuzuki and A. Kawaguchi, "Impaired photosystem II in a mutant of Chlamydomonas reinhardtii defective in sulfoquinovosyl diacylglycerol", Eur Journal Biochem, vol. 234, (1995), pp. 16-23.

[25] L. Zhang, T. Happe and A. Melis, "Biochemical and morphological characterization of sulfur-deprived and H2-producing Chlamydomonas reinhardtii (green alga)", Planta, vol. 214, (2002), pp. 552-561.

[26] A. Grossman and H. Takahashi, "Macronutrient utilization by photosynthetic eukaryotes and the fabric of interactions", Annu. Rev. Plant Physiol, vol. 52, (2001), pp. 163-210.

[27] K. Vijayaraghavan, D. Yamini, V. Ambika and S. Sowdamini, N., "Trends in inulinase production-a review", Critical Reviews in Biotechnology, vol. 29, (2009), pp. 67-77.

[28] K. Skjånes, C. Rebours and P. Lindblad, "Potential for green microalgae to produce hydrogen, pharmaceuticals and other high value products in a combined process", Critical Reviews in Biotechnology, vol. 33, no. 2, (2013), pp. 172-215.

[29] H. Long, C. H. Chang, P. W. King, M. L. Ghirardi and K. Kim, "Brownian dynamics and molecular dynamics study of the association between hydrogenase and ferredoxin from Chlamydomonas reinhardtii”, Biophys Journal, vol. 95, (2008), pp. 3753-3766.

[30] A. Hemschemeier, S. Fouchard, L. Cournac, G. Peltier and T. Happe, "Hydrogen production by Chlamydomonas reinhardtii: an elaborate interplay of electron sources and sinks", Planta., vol. 227, no. 2, (2008), pp. 397-407.

[31] M. Timmins, S. R. Thomas-Hall, A. Darling, E. Zhang, B. Hankamer, U. C. Marx and P. M. Schenk, P. M., "Phylogenetic and molecular analysis of hydrogen-producing green algae", Journal Exp. Bot., vol. 60, (2009), pp. 1691-1702.

[32] N. Rashid, K. Lee and Q. Mahmood, "Bio-hydrogen production by Chlorella vulgaris under diverse photoperiods", Bioresource Technology, vol. 102, no. 2, (2011), pp. 2101-2104.

[33] S. N. Kosourov and M. Seibert, "Hydrogen photoproduction by nutrient-deprived Chlamydomonas reinhardtii cells immobilized within thin alginate films under aerobic and anaerobic conditions", Biotechnology and Bioengineering, vol. 102, (2009), pp. 50-58.

[34] T. V. Laurinavichene, I. V. Tolstygina, R. R. Galiulina, M. L. Ghirardi, M. Seibert and A. Tsygankov, "Dilution methods to deprive Chlamydomonas reinhardtii cultures of sulfur for subsequent hydrogen photoproduction”, Int Journal Hydrogen Energy, vol. 27, (2002), pp. 1245-1249.

[35] M. L. Ghirardi, "Hydrogen production by photosynthetic green algae", Indian Journal Biochem Biophys, vol. 43, no. 4, (2006), pp. 201-120.

[36] A. Tsygankov, S. Kosourov, M. Seibert and M. Ghirardi, "Hydrogen photoproduction under continuous illumination by sulfur-deprived, synchronous Chlamydomonas reinhardtii cultures", International Journal of Hydrogen Energy, vol. 27, no. 11-12, (2002), pp. 1239-1244.

[37] X. Li, S. Huang, J. Yu, Q. Wang and S. Wu, "Improvement of hydrogen production of Chlamydomonas reinhardtii by co-cultivation with isolated bacteria", International Journal of Hydrogen Energy, vol. 38, no. 25, (2013), pp. 10779-10787.

[38] R. Wirth, G. Lakatos, G. Maróti, Z. Bagi, J. Minárovics and K. Nagy, "Exploitation of algal-bacterial associations in a two-stage biohydrogen and biogas generation process", Biotechnology for Biofuels, vol. 8, no. 1, (2015), pp. 1-14.

[39] A. Kouzuma and K. Watanabe, "Exploring the potential of algae/bacteria interactions", Current Opinion in Biotechnology, vol. 33, (2015), pp. 125-129.

[40] A. Melis and M. Melnicki, "Integrated biological hydrogen production”, Int. J. Hydrogen Energy, vol. 31, (2006), pp. 1563-1573.

[41] M. Bao, H. Su and T. Tan, "Biohydrogen production by dark fermentation of starch using mixed bacterial cultures of Bacillus sp and Brevumdimonas sp.”, Energy and Fuels, vol. 26, (2012), pp. 58725878.

[42] S. K. Patel, P. Kumar, S. Mehariya, H. J. Purohit, J. K. Lee and V. C. Kalia, "Enhancement in hydrogen production by co-cultures of Bacillus and Enterobacter", International Journal of Hydrogen Energy, vol. 39, (2014), pp. 14663-14668.

\section{Authors}

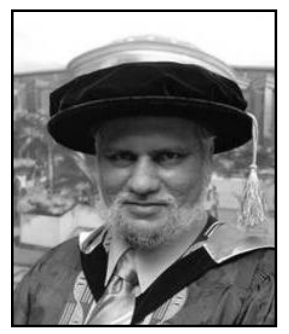

Saifuddin Nomanbhay, he is in the last 18 years at UNITEN, he has been actively involved in the research the field of microwave assisted reactions, biocatalyst immobilization and biodiesel/bioethanol production. $\mathrm{He}$ is currently the principal researcher at the Centre for Renewable Energy Research (CRE) of UNITEN. His research now is more focus on renewable resources and enabling technologies. He has substantial volume of refereed research publications (more than 53 journal papers and 13 conference papers), and a book. 


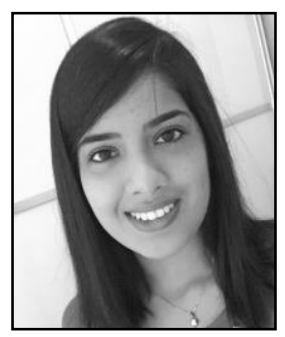

Priatharsini Puvunathan, she received her Bachelor of Science in Biomedical Science from University of Adelaide in year 2012. On June 2015, she joined UNITEN as a master student in Industrial Science.

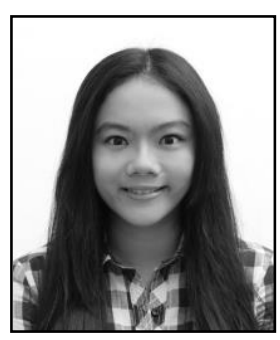

Ong Mei Yin, she graduated on March 2016 with Bachelor of Mechanical Engineering (Hons.) at UNITEN where she continued her master study in Mechanical Engineering on November 2016. 